\title{
Research on the Convergence of Regional Economic Growth in China
}

\author{
Jiajin Bao; Jingzi Wang; Yingjun Mo; Chuangui Tong; Cheng Liu* \\ Department of Mathematics \\ Southwest Jiaotong University \\ Chengdu, China \\ 1031095560@qq.com; 2420539566@qq.com; 2785306392@qq.com; 1521588895@qq.com; 1554047784@qq.com
}

\begin{abstract}
The study was designed to analyze the economic growth convergence from year 2008 to 2015 in 19 coastal and border provinces (districts) in China. To provide a more comprehensive and objective analysis on the economic growth, we collected real GDP per capita of 19 selected provinces in the 8 years, and utilized four distinct methods of econometrics, which are $\sigma-$ Convergence, absolute $\beta-$ Convergence, club convergence and quantile regression. $\sigma$ - Convergence was conducted in Gini coefficient method and Theil index methods. And we used SLM model and SEM model to explore the effect of spatial interaction in $\beta$-Convergence. The results suggests that the economic growth of overall provinces shows the trend of $\sigma-$ Convergence, and there exists absolute $\beta$-Convergence in coastal and border provinces. However, there is no co-integration between the two regions. The study is of some importance in the state policy on economic growth.
\end{abstract}

Keywords-econometrics; economic growth convergence; $\sigma$-convergence; $\beta$-convergence; club convergence; quantile regression

\section{INTRODUCTION}

In 1997, China entered the period of building a well-off society in an all-round way, General Secretary Xi Jinping pointed out that we must firmly grasp the requirement of "building a well-off society in an all-round way", coordinate development and strive to narrow the gap in order to achieve common prosperity, that is to construct a society with strong comprehensive national strength and economic, political and cultural coordination. All the time, economic growth and economic growth convergence are the focus of empirical research in Economics. And with the deepening of reform and opening up, especially the acceleration of the process of marketization, production factors such as capital and labor force gather under the guidance of market mechanism, making the quality and efficiency of China's economic growth improve significantly, and meanwhile, people begin to pay close attention to how to narrow regional gap and realizes regional economic growth convergence.

Convergence of economic growth refers to the fact that under the closed economic conditions, due to the high capital marginal output, backward economies develop the economy at a rate higher than that of developed economies, so as to gradually eliminate the static index difference in the early stage of economic development, that is, backward economies tend to approach and close developed economies continuously and eventually reach their stable state. Convergent economy depicts people's common happiness index, under the premise of narrowing the economic development differences between regions. And taking factors such as the history, geographical location, national regional development policies into account, we found that hitherto regional economic development in China still exists bigger difference. At this point, studying China's regional economic development is conducive to better implementation of relevant policies to promote the balanced development of regional economy.

\section{LITERATURE REVIEW}

Convergence of regional economic growth refers to the process of gradual reduction in the level of per capita output (GDP) in different regions over time. Since Solow (1956) [1] proposed economic growth convergence hypothesis, many scholars have put forward different methods to test the economic convergence, including $\sigma$-convergence, $\beta$-convergence, club convergence and quantile regression, and use them to analyze the convergence in different economic range.

Among them, in the study of China's economic convergence, CHEN Xiaoling and LI Guoping [2] found that since 1978, the spatial dependence of China's economy has gradually strengthened, the agglomeration of the regional economy has increased, showing that spatial interaction may have a significant impact on China's economic development. When utilizing Moran I index to study the spatial pattern of regional economy in china, HONG Guozhi, HU Huaying, LI Yong (2010) [3] found that GDP per capita has a strong global positive autocorrelation between 1990 and 2007, meanwhile, the results of the spatial econometric analysis also show that urban economic development in China has absolute $\beta$ convergence. However, from research on the regional economic growth of China in 1953-2010, HE Xionglang, ZHENG Changde et al. (2013) [4] found that although the spatial correlation of regional development in China has been increasing year by year, there is no absolute $\beta$ convergence, but when the fiscal policy and human capital influence factors are added, economic growth in China exists conditional $\beta$ convergence. At the same time, CAI Fang, DU Yang (2000) [5] found that there exists club convergence and conditional convergence phenomenon in China's economic growth, when 
utilizing Theil index and neoclassical economic model to carry out an empirical research on China's regional economic growth convergence.

\section{DATA COLLECTION\&DESCRIPTION}

In the study of economic growth convergence, selecting measurable index of economic development level is necessary.

Taking the representation of GDP per capita into account in measuring the level of regional economic development and the people's living conditions, we select it as main macroeconomic indicator to study the convergence of China's economic growth and make quantitative analysis. Secondly, when examining economic convergence, we identify 12 explanatory variables from five aspects: economic strength, fiscal policy disturbance, economic benefit of foreign trade, industrial structure and urban traffic construction. Actually, we consider using material capital: GDP per capita(explanatory variables),total investment in fixed assets, the total retail sales of social consumer goods, residents' consumption level and consumer price index(CPI) to measure the economic development strength of the provinces; using local budgetary revenue and local fiscal general budget expenditure to characterize fiscal policy disturbance; with the degree of opening to the outside world: the ratio of total amount investment of foreign - invested enterprises to GDP(FDI/GDP), the ratio of total import and export to GDP to examine the economic benefits of foreign trade; industrial structure: the second industry output value/GDP, the tertiary industry output value/GDP; and through the road area, per capita Road area indicators to measure the degree of traffic development. Above indicators have simple definition and the characteristic of being representative and accessible, and to some extent, they can explain the problem.

With reference to coastal and border opening-up provinces in China[6], we finally selected Zhejiang, Shanghai, Guangdong, Jiangsu, Fujian, Hainan, Tianjin, Liaoning as the representative of coastal provinces and cities and Guangxi, Xinjiang, Shanxi, Gansu, Yunnan, Inner Mongolia, Ningxia, Tibet, Heilongjiang, Shaanxi, Qinghai as the representative of border provinces and cities, to study the convergence of relevant economic growth.

All macroeconomic variables are derived from a single data source, which is the official website of National Bureau of Statistics of the People's Republic of China.

\section{DESCRIPTIVE STATISTICS\&ANALYSIS OF ACTUAL LABOR PRODUCTION (GDP PERCAPITA)}

GDP per capita is an important indicator to measure the level of regional economic development, through the descriptive statistical analysis of per capita GDP of coastal and border provinces in China, we are able to make a global judgment of the overall economic situation of the above areas, which is beneficial for the follow-up study the convergence of economic growth in China's coastal and border provinces by different convergence methods.
TABLE I D DESCRIPTIVE STATISTICS OF GDP PER CAPITA OF THE WHOLE COASTAL AND BORDER PROVINCES

\begin{tabular}{|c|c|c|c|c|c|}
\hline Year & Maximum & Minimum & SD & Median & Mean \\
\hline 2008 & 66932.00 & 12421.00 & 15436.74 & 21506.00 & 28037.00 \\
\hline 2009 & 69165.00 & 13269.00 & 16281.07 & 21947.00 & 30094.47 \\
\hline 2010 & 76074.00 & 15752.00 & 18142.42 & 27076.00 & 35659.00 \\
\hline 2011 & 85213.00 & 19265.00 & 20079.51 & 33043.00 & 42088.58 \\
\hline 2012 & 93173.00 & 21978.00 & 21118.47 & 36394.00 & 46124.84 \\
\hline 2013 & 100105.00 & 24539.00 & 22418.00 & 39613.00 & 50236.68 \\
\hline 2014 & 105231.00 & 26433.00 & 23742.13 & 41834.00 & 53631.89 \\
\hline 2015 & 107960.00 & 25105.00 & 25105.02 & 43805.00 & 55757.74 \\
\hline Year & $\mathbf{1}^{\text {st }}$ Quantile & $\mathbf{2}^{\text {nd }}$ Quantile & $\mathbf{3}^{\text {rd }}$ Quantile & C.V. \\
\hline 2008 & 14652.00 & 19797.00 & 34869.00 & 0.55 \\
\hline 2009 & 16045.00 & 21777.00 & 39436.00 & 0.54 \\
\hline 2010 & 20219.00 & 26860.00 & 44736.00 & 0.51 \\
\hline 2011 & 25326.00 & 32819.00 & 50807.00 & 0.48 \\
\hline 2012 & 27952.00 & 35711.00 & \multicolumn{2}{|c|}{56649.00} & 0.46 \\
\hline 2013 & 30741.00 & 37697.00 & 61996.00 & 0.45 \\
\hline 2014 & 33090.00 & 33090.00 & \multicolumn{2}{|c|}{65201.00} & 0.44 \\
\hline 2015 & 34919.00 & 34919.00 & \multicolumn{2}{|c|}{67966.00} & 0.45 \\
\hline
\end{tabular}

The table gives out partial descriptive statistics of GDP per capita in the whole coastal and border provinces, the maximum, minimum, and the standard deviation depict the discrete degree of sample; while the median, mean value and quantile depict the central tendency of sample. We can see from this table that for the selected coastal and border provinces, the overall economic growth rate has slowed, but GDP per capita value still has greatly improved. The increase of standard deviation shows that when all provinces are developing economy, the discrete degree of GDP per capita is gradually increasing. The increase of median, mean value and quantile indicates that as a whole, economy in coastal and border provinces from 2008 to 2015 has developed quickly. In addition, the fact that mean value rises to 1.63 times explains areas with higher development degree will be surrounded by other areas of better development, while areas with lower development degree will be surrounded by other areas with poorer development, that means regional economic development may show a relationship of correlation. Coefficient of variation describes the output level gap of each province, although the variation of coefficient of variation is not obvious but still shows a slight downward trend, indicating the discrete degree of economic development level is shrinking. That is, there may be convergence phenomenon in the regional economy.

\section{V.REGIONAL ECONOMIC GROWTH CONVERGENCE MODELS \& RELEVANT CONCEPTS}

\section{A. $\sigma$-Convergence Hypothesis}

\section{1) The Concepts of $\sigma$-Convergence}

$\sigma-$ Convergence demonstrates the progress that the level of output or income per capita in different countries or districts decreases as time goes, to research the overall development of the regional economy based on the variance convergence of economy difference. In the literature on economic convergence hypothesis, the measuring method of $\sigma$-convergence in regional economic growth mostly focus on the discrepancy in terms of the levels of different districts' output or income per capita.

\section{2) The Measure of $\sigma-$ Convergence}

The main methods of measuring $\sigma$-convergence are variance decomposition method, Gini coefficient method, Theil index method, standard deviation method and so on. Due to the different focal points of every method, it is necessary to 
combine several methods to reach the more accurate conclusion on the research of $\sigma$-convergence. This paper use Gini coefficient method and Theil index method to construct the $\sigma$-convergence analysis on the economic growth of coastal and border provinces (districts) in China.

\section{3) Gini Coefficient Method}

The calculation of Gini coefficient generally relies on Lorenz curve, to examine the uneven distribution of residents' income in some economic sphere. However, the calculation on the unknown Lorenz curve is always substituted by half of the relative mean absolute difference, where the mean absolute difference is the average absolute difference of real GDP per capita between districts. The formula of Gini coefficient is shown as follows [7].

$$
G=\frac{\sum_{i=1}^{n} \sum_{j=1}^{n}\left|x_{i}-x_{j}\right|}{2 \sum_{i=1}^{n} \sum_{j=1}^{n} x_{j}}=\frac{\sum_{i=1}^{n} \sum_{j=1}^{n}\left|x_{i}-x_{j}\right|}{2 n \sum_{i=1}^{n} x_{i}}
$$

Where, $x_{i}, x_{j}$ are the two districts' real GDP per capita, $\mathrm{n}$ is the number of districts.

\section{4) Theil Index Method}

Theil index method is superior by decomposition, to weigh the respective contribution of differences between groups and within groups to the overall difference. For example, n samples can be distributed into $K$ groups with $n_{k}$ samples in the group $g_{k}\left(\sum_{k=1}^{K} n_{k}=n\right)$, in which $y_{i}$ is the income share of the sample I and $y_{k}$ is the total income share of group k. $T_{b}$ and $T_{w}$ represent the differences between groups and within groups. The formula of Theil index method is shown as follows [8].

$$
\mathrm{T}=\mathrm{T}_{\mathrm{b}}+\mathrm{T}_{\mathrm{w}}=\sum_{\mathrm{k}=1}^{\mathrm{k}} \mathrm{y}_{\mathrm{k}} \log \frac{\mathrm{y}_{\mathrm{k}}}{\frac{\mathrm{n}_{\mathrm{k}}}{\mathrm{n}}}+\sum_{\mathrm{k}=1}^{\mathrm{k}} \mathrm{y}_{\mathrm{k}}\left(\sum_{\mathrm{i} \in \mathrm{g}_{\mathrm{k}}} \frac{\mathrm{y}_{\mathrm{i}}}{\mathrm{y}_{\mathrm{k}}} \log \frac{\frac{\mathrm{y}_{\mathrm{i}}}{\mathrm{y}_{\mathrm{k}}}}{\frac{1}{\mathrm{n}_{\mathrm{k}}}}\right)
$$

The difference between groups is shown as follows.

$$
\mathrm{T}_{\mathrm{b}}=\sum_{\mathrm{k}=1}^{\mathrm{k}} \mathrm{y}_{\mathrm{k}} \log \frac{\mathrm{y}_{\mathrm{k}}}{\frac{\mathrm{n}_{\mathrm{k}}}{\mathrm{n}}}
$$

The difference within groups is shown as follows.

$$
\mathrm{T}_{\mathrm{w}}=\sum_{\mathrm{k}=1}^{\mathrm{K}} \mathrm{y}_{\mathrm{k}}\left(\sum_{\mathrm{i} \in \mathrm{g}_{\mathrm{k}}} \frac{\mathrm{y}_{\mathrm{i}}}{\mathrm{y}_{\mathrm{k}}} \log \frac{\frac{\mathrm{y}_{\mathrm{i}}}{\mathrm{y}_{\mathrm{k}}}}{\frac{1}{\mathrm{n}_{\mathrm{k}}}}\right)
$$

It is available to examine the difference of the income share between every economy in this economic region. A larger value of the Theil index suggests a bigger difference. We can observe the overall developing trend in the economic region via the analysis on Theil index in the time sequence [9].

\section{B. $\beta$-Convergence Hypothesis}

$\beta$ - Convergence is generally divided into absolute $\beta$-convergence and conditional $\beta$-convergence. Absolute $\beta$-convergence refer to poor economies developing to narrow the gap with rich economies in a higher speed and the both level of GDP per capita tending to a steady state regardless the initial condition and structural system such as natural resources, technique level. In comparison, conditional $\beta$-convergence measures the regional development level by actual quantifiable indicators with the direct or indirect influence from the resource endowment statuses of each district.

This paper utilizes neoclassical growth theory into the spatial panel data model (SPDM) to have a convergence analysis on the economic development of China's coastal and border provinces, in the method of cross sectional regression, and under the assumption that economies are homogeneous. The test on the spatial correlation of each section unit has the priority to determine the applicability of spatial panel data.

\section{1) Spatial Correlation}

Spatial correlation is divided into global relevance and local relevance by the scope of research, which respectively measured the global Moran index and the local one. In contrast to the global Moran index which reflects the overall spatial correlation, the local one is applied to measure the correlation in a local economic region. Moran index varies from -1 to 1 , indicting the correlation from completely negative to positive, and shows no correlation when it equals to the expected value [10]. The calculation is defined as follows [11].

$$
I=\frac{n}{S_{0}} \frac{\sum_{i=1}^{n} \sum_{j=1}^{n} w_{i j}\left(x_{i}-x\right)\left(x_{j}-x\right)}{\sum_{i=1}^{n}\left(x_{i}-\bar{x}\right)^{2}}
$$

$$
\mathrm{Z}_{\mathrm{I}}=\frac{\mathrm{I}-\mathrm{E}(\mathrm{I})}{\sqrt{\mathrm{V}(\mathrm{I})}}
$$

$$
\mathrm{E}(\mathrm{I})=\frac{-1}{\mathrm{n}-1}
$$

$$
\mathrm{V}(\mathrm{I})=\mathrm{E}\left(\mathrm{I}^{2}\right)-(\mathrm{E}(\mathrm{I}))^{2}
$$

$$
\begin{aligned}
\text { Where, } S_{0}= & \sum_{i=1}^{n} \sum_{j=1}^{n} w_{i j}, E\left(I^{2}\right)=\frac{A-B}{C}, \\
A= & n\left[\left(n^{2}-3 n+2\right) S_{1}-n S_{2}+3 S_{0}^{2} 2\right], \\
B & =D\left[\left(n^{2}-n\right) S_{1}-2 n S_{2}+6 S_{0}^{2}\right]
\end{aligned}
$$




$$
\begin{aligned}
C=(n-1)(n-2)(n-3) S_{0}^{2}, D & =\frac{\sum_{i=1}^{n}\left(x_{i}-x\right)^{4}}{\left(\sum_{i=1}^{n}\left(x_{i}-x\right)^{2}\right)^{2}} \\
S_{1} & =1 / 2 \sum_{i=1}^{n} \sum_{j=1}^{n}\left(w_{i j}+w_{j i}\right)^{2} \\
S_{2} & =\sum_{i=1}^{n}\left(\sum_{j=1}^{n} w_{i j}+\sum_{j=1}^{n} w_{j i}\right)^{2}
\end{aligned}
$$

$w_{i j}$ denote the spatial weight matrix calculated according to the way in Shi Xiusong and Zhao Shudong (2011) [11], that $w_{i j}$ equals to 1 when the provinces $\mathrm{i}$ and $\mathrm{j}$ are adjacent, otherwise it equals to 0 .

\section{1) Spatial Panel Date Model}

Spatial panel data model differs from the common panel data model in the addition of spatial interaction effect between explained variables. Under the given initial economic growth level, the model reveals how the economic growth rate of one district is affected by that of adjacent area. [3]

\section{2) Spatial Lag Model (Spatial Autoregressive Model)}

The SLM model of absolute $\beta$-convergence is set up as follows [12].

$\ln \left(\mathrm{ER}_{\mathrm{i}, \mathrm{t}+1}\right)=\alpha+\beta \ln \left(\mathrm{GDP}_{\mathrm{i}, \mathrm{t}}\right)+\delta \sum_{\mathrm{j}=1}^{\mathrm{n}} \mathrm{w}_{\mathrm{ij}} \ln \left(\mathrm{ER}_{\mathrm{i}, \mathrm{t}+1}\right)+\mathrm{u}_{\mathrm{i}, \mathrm{t}+1}(9)$

Where, $E R_{i, t+1}=\frac{G D P_{i, t+1}}{G D P_{i, t}}$ refers to the economic growth rate (that is ratio of real GDP per capita in this year to the one in last year with data in logarithmic mode, in the unit of \%), $\delta$ is spatial autoregressive coefficient, $w_{i j}$ is spatial weight matrix mentioned above.

\section{3) Spatial Error Model}

Spatial error model is developed on the common panel data model by adding the spatial interaction effect of random disturbance term, which reflects the interaction of spatial individuals.

The SEM model of absolute $\beta$-convergence is set up as follows.

$$
\begin{gathered}
\left.\ln \left(\mathrm{ER}_{\mathrm{i}, \mathrm{t}+1}\right)\right)=\alpha_{\mathrm{i}}+\beta \ln \left(\mathrm{GDP}_{\mathrm{i}, \mathrm{t}}\right)+\mathrm{u}_{\mathrm{it}+1} \\
\mathrm{u}_{\mathrm{it}+1}=\rho \sum_{\mathrm{j}=1}^{\mathrm{n}} \mathrm{w}_{\mathrm{ij}} \mathrm{u}_{\mathrm{jt}+1}+\eta_{\mathrm{it}+1}
\end{gathered}
$$

Where, $\alpha_{i}$ represent the intercept items, $\sum_{j=1}^{n} w_{i j} u_{j t+1}$ is the spatial lag factor of random disturbance term, and $\eta_{i t+1}$ is the random disturbance term.

\section{Club Convergence Hypothesis}

Club Convergence refers to the fact that economies with similar initial conditions and structures converge to the same steady state. Currently, judgment of club convergence goes in the aspects of time and space. The time sequence method determines whether the discrepancy of each area's GDP per capita diminishes in the long term according to the analysis on the existence of unit root or same trend between different regions, so as to research the economic growth convergence. [13]

According to the definition on convergence and mutual trend in Bernard and Durlarf (1996) [14], the core of research on economic growth convergence is to determine the number of co-integration relationships in the time sequence of GDP per capita. When the number $r=p-1$, there exists the converging trend in the economic growth, and there will be no such trend if $r<p-1$.

The test on the number of co-integration relationships is usually carried on in the maximum likelihood method byJohanson. And the trace statistics are constructed as:

$$
L R_{r}=-n \sum_{i=r+1}^{p} \ln \left(1-\lambda_{i}\right)(r=0,1, \ldots, p-1)
$$

Where $\mathrm{p}$ is the number of time sequence variables in the vector $Y_{t}, \mathrm{n}$ is the sample size, $\lambda_{i}$ is the maximum characteristic root in step $\mathrm{i}, \mathrm{r}$ refers to the number of co-integration relationships which varies from 0 to $\mathrm{p}-1$.

\section{Quantile Regression}

The regression analysis of explanatory variables and explained variables generally focus on the mean analysis. Since Koenker and Bassett(1978) [15] firstly proposed the concept of mean analysis and set up models in the core of the conditional quantile of the dependent variable, quantile regression can be treated as the extend of least squares regression. Suppose the distribution function of the continuous single random variable is $F_{Y}(y)=P(Y \leq y)$, then its $\tau$ quantile can be defined as:

$$
Q_{\tau}(Y)=\inf \left\{y: F_{Y}(y) \geq \tau\right\}, \tau \in(0,1)
$$

For example, divide the sample into four equal parts, then the first quantile denotes as $Q(0.25)$, the second one is $Q(0.5)$ and so on.

Suppose the $\tau$ quantile of explained variable under the explanatory variable is:

$$
Q_{\tau}(Y \mid X)=\inf \left\{y: F_{Y \mid X}(y) \geq \tau\right\}, \tau \in(0,1)
$$

Where $F_{Y \mid X}(y)$ denotes the conditional distribution of continuous random variable $\mathrm{Y}$ under the givenX, $Q_{\tau}(Y \mid X)$ is the function of $\mathrm{X}$, and $\mathrm{g}(\mathrm{X})=\mathrm{Q}_{\tau}(\mathrm{Y} \mid \mathrm{X})=\mathrm{X}^{\prime} \cdot \beta_{\tau}$ in the general linear model $Y=\alpha_{\tau}+\beta_{\tau} \cdot X^{\prime}+u_{\tau}(i=1,2 、 3 \ldots)$, as the regression parameters, $\alpha_{\tau}$ and $\beta_{\tau}$ refer to intercept items and slope terms, $u_{\tau}$ denotes the random disturbance term.

The parameter estimation of quantile regression aims to 
minimize the weighted absolute residual value, that to decrease the absolute difference between explained variable $\mathrm{y}$ and its fit value. The linear quantile regression model is

$$
\left\{\begin{array}{l}
g(X)=Q_{\tau}(Y \mid X)=X^{\prime} \cdot \beta_{\tau} \\
Y=\alpha_{\tau}+X^{\prime} \cdot \beta_{\tau}+u_{\tau}
\end{array}\right.
$$

The parameter satisfies the relationship as follows:

$$
\beta_{\tau}=\arg \min _{\alpha, \beta} E\left\{\rho_{\tau}\left(Y-\alpha_{\tau}-X^{\prime} \cdot \beta_{\tau}\right)\right\}
$$

Where $\rho_{\tau}(\mathrm{z})=\mathrm{z}(\tau-I(z<0))$ is the weight corresponding to each quantile.

\section{THE EMPIRICAL RESEARCH ON CHINA'S REGIONAL ECONOMIC CONVERGENCE}

Based on the models above, we conduct the economic convergence analysis in the use of data accessed on line from 2008 to 2015.

\section{A. The Empirical Research on $\sigma$-Convergence of China's}

Coastal and Border Provinces (Districts) Economic Growth

\section{1) The Method of Gini Coefficient}

The Gini coefficient of GDP per capita in coastal, border and the whole province are calculated by the forum of Gini coefficient as follows:

TABLE II. GINI COEFFICIENT OF GDP PER CAPITA IN COASTAL, BORDER AND THE WHOLE PROVINCES

\begin{tabular}{|c|c|c|c|}
\hline Year & Coastal & Border & The whole \\
\hline 2008 & 0.2009 & 0.1604 & 0.2826 \\
\hline 2009 & 0.1896 & 0.1637 & 0.2797 \\
\hline 2010 & 0.1758 & 0.1650 & 0.2668 \\
\hline 2011 & 0.1641 & 0.1666 & 0.2529 \\
\hline 2012 & 0.1576 & 0.1628 & 0.2439 \\
\hline 2013 & 0.1527 & 0.1546 & 0.2381 \\
\hline 2014 & 0.1480 & 0.1517 & 0.2365 \\
\hline 2015 & 0.1481 & 0.1457 & 0.2400 \\
\hline
\end{tabular}

From the chart, the continuous decreasing of Gini coefficient in coastal provinces indicates the gentle converging trend. In contrast, the Gini coefficient of GDP per capita in border provinces experiences two stages, which correspond to the trend of diverging and converging. In generally, the Gini coefficient of the whole provinces converges to a relative steady state as the value decreases year by year except the year 2015.

In conclusion, from year 2008 to 2015, the 8 coastal provinces or districts in China such as Zhejiang, Shanghai shows $\sigma$-convergence, and it is the same in the whole provinces. Nevertheless, there is no convergence in the coastal provinces or districts.

\section{2) The Method of Theil Index}

With using the forum of Theil index, the difference within and between the groups of 19 provinces are calculated as follows:
TABLE III. THEIL INDEX OF GDP PER CAPITA IN COASTAL AND BORDER PROVINCES IN CHINA

\begin{tabular}{|c|c|c|c|c|c|c|}
\hline Year & $\begin{array}{c}\text { With } \\
\text { in } \\
\text { Grou } \\
\text { ps }\end{array}$ & $\begin{array}{c}\text { In } \\
\text { Coastal } \\
\text { District } \\
\text { s }\end{array}$ & $\begin{array}{c}\text { In } \\
\text { Border } \\
\text { Districts }\end{array}$ & $\begin{array}{c}\text { Overall } \\
\text { Differen } \\
\text { ce }\end{array}$ & $\begin{array}{c}\text { Proporti } \\
\text { on of } \\
\text { Coastal } \\
\text { Districts }\end{array}$ & $\begin{array}{c}\text { Proporti } \\
\text { on of } \\
\text { Border } \\
\text { Districts }\end{array}$ \\
\hline 2008 & 0.031 & 0.018 & 0.008 & 0.056 & 0.314 & 0.140 \\
\hline 2009 & 0.030 & 0.016 & 0.009 & 0.055 & 0.290 & 0.158 \\
\hline 2010 & 0.027 & 0.014 & 0.009 & 0.050 & 0.272 & 0.180 \\
\hline 2011 & 0.023 & 0.012 & 0.009 & 0.044 & 0.261 & 0.212 \\
\hline 2012 & 0.021 & 0.010 & 0.009 & 0.041 & 0.255 & 0.221 \\
\hline 2013 & 0.021 & 0.010 & 0.008 & 0.039 & 0.251 & 0.207 \\
\hline 2014 & 0.022 & 0.009 & 0.008 & 0.038 & 0.242 & 0.197 \\
\hline 2015 & 0.023 & 0.009 & 0.007 & 0.040 & 0.237 & 0.173 \\
\hline
\end{tabular}

From the chart: the difference of GDP per capita in coastal provinces shrinks fast in the first five years and slowly later, which shows the $\sigma$-convergence trend in the economic growth of coastal provinces. But the overall change in the internal difference of border provinces does not have a significant converging trend. With the analysis on the proportion of coastal and border provinces in the whole provinces, it is obvious to find that the difference between two regions contributes a relative changeless proportion in the whole difference, and the higher proportion of differences in coastal provinces contributes to the $\sigma$-convergence trend of the whole provinces.

\section{B. The Empirical Research on $\beta$-Convergence of China's Coastal and Border Provinces (districts) Economic Growth}

\section{1) Spatial Correlation}

During the research on the coastal and border provinces' economic growth in China, we calculate the Moran index and relative statistics in the scale of coastal, border and the whole region with using the software MATLAB, and operate the test under the level of $5 \%$. The results are as follows:

TABLE IV. THE MORAN INDEX AND RELATIVE STATISTICS OF THE WHOLE REGION

\begin{tabular}{|c|c|c|c|c|}
\hline Year & Moran I & $\mathbf{Z}_{\mathbf{I}}$ & Z-alpha & E_I \\
\hline 2008 & 0.4462 & 2.6609 & 1.6449 & -0.0556 \\
\hline 2009 & 0.4566 & 2.7157 & 1.6449 & -0.0556 \\
\hline 2010 & 0.4764 & 2.8209 & 1.6449 & -0.0556 \\
\hline 2011 & 0.4668 & 2.7702 & 1.6449 & -0.0556 \\
\hline 2012 & 0.4522 & 2.6925 & 1.6449 & -0.0556 \\
\hline 2013 & 0.4523 & 2.6930 & 1.6449 & -0.0556 \\
\hline 2014 & 0.4540 & 2.7023 & 1.6449 & -0.0556 \\
\hline 2015 & 0.4880 & 2.8824 & 1.6449 & -0.0556 \\
\hline
\end{tabular}

TABLE V. THE MORAN INDEX AND RELATIVE STATISTICS OF THE COASTAL (UPPER) AND BORDER (BOTTOM)

\begin{tabular}{|c|c|c|c|c|}
\hline Year & Moran I & $\boldsymbol{Z}_{\boldsymbol{I}}$ & Z-alpha & E_I \\
\hline 2008 & 0.0968 & 0.6967 & 1.6449 & -0.1429 \\
\hline 2009 & 0.1564 & 0.8701 & 1.6449 & -0.1429 \\
\hline 2010 & 0.2362 & 1.1019 & 1.6449 & -0.1429 \\
\hline 2011 & 0.2888 & 1.2548 & 1.6449 & -0.1429 \\
\hline 2012 & 0.3256 & 1.3617 & 1.6449 & -0.1429 \\
\hline 2013 & 0.3456 & 1.4199 & 1.6449 & -0.1429 \\
\hline 2014 & 0.3487 & 1.4291 & 1.6449 & -0.1429 \\
\hline 2015 & 0.3598 & 1.4613 & 1.6449 & -0.1429 \\
\hline Year & Moran I & $\boldsymbol{Z}_{\boldsymbol{I}}$ & $\mathbf{Z}$-alpha & E_I \\
\hline 2008 & 0.2873 & 1.6896 & 1.6449 & -0.1000 \\
\hline 2009 & 0.2136 & 1.3684 & 1.6449 & -0.1000 \\
\hline 2010 & 0.2179 & 1.3869 & 1.6449 & -0.1000 \\
\hline 2011 & 0.2012 & 1.3139 & 1.6449 & -0.1000 \\
\hline
\end{tabular}




\begin{tabular}{|l|c|c|c|c|}
\hline \multicolumn{5}{|c|}{ Table V, cont. } \\
\hline 2012 & 0.1563 & 1.1183 & 1.6449 & -0.1000 \\
\hline 2013 & 0.0824 & 0.7956 & 1.6449 & -0.1000 \\
\hline 2014 & 0.0082 & 0.4723 & 1.6449 & -0.1000 \\
\hline 2015 & -0.0562 & 0.1909 & 1.6449 & -0.1000 \\
\hline
\end{tabular}

We can know from the tables above that the overall Moran index develops in an increasing tendency and changes from 0.4462 to 0.4880 through three stages with a drop between two periods of rising. The Moran index of coastal provinces demonstrates that the spatial distribution of economic activities in the coastal region has a significant influence on economic growth, while the spatial correlation of border provinces declines year by year from the positive correlation to the negative one. It is obvious that spatial development also depends on the correlation with the surrounding area, not only its own historical developing course. Therefore, it is necessary to consider the spatial factor into the analysis.

\section{2) The Result of $\beta$-Convergence Analysis}

TABLE VI. THE REGRESSION RESULTS OF SLM MODEL AND SEM MODEL

\begin{tabular}{|c|c|c|c|c|c|}
\hline Coastal & $\boldsymbol{\beta}$ & $\boldsymbol{\delta}$ & $\mathbf{t}_{\boldsymbol{\beta}}$ & $\mathbf{t}_{\boldsymbol{\delta}}$ & $\mathbf{R}^{\mathbf{2}}$ \\
\cline { 2 - 6 } Area & -0.063 & 0.062 & -4.733 & 1.387 & 0.323 \\
\hline Border & $\boldsymbol{\beta}$ & $\boldsymbol{\delta}$ & $\mathbf{t}_{\boldsymbol{\beta}}$ & $\mathbf{t}_{\boldsymbol{\delta}}$ & $\mathbf{R}^{\mathbf{2}}$ \\
\cline { 2 - 6 } Area & -0.092 & -0.311 & -4.544 & -2.030 & 0.219 \\
\hline All & $\boldsymbol{\beta}$ & $\boldsymbol{\delta}$ & $\mathbf{t}_{\boldsymbol{\beta}}$ & $\mathbf{t}_{\boldsymbol{\delta}}$ & $\mathbf{R}^{\mathbf{2}}$ \\
\cline { 2 - 6 } Area & -0.005 & 0.762 & -0.676 & 11.814 & 0.597 \\
\hline $\begin{array}{c}\text { Coastal } \\
\text { Area }\end{array}$ & $\boldsymbol{\beta}$ & $\boldsymbol{\rho}$ & $\mathbf{t}_{\boldsymbol{\beta}}$ & $\mathbf{t}_{\boldsymbol{\rho}}$ & $\mathbf{R}^{\mathbf{2}}$ \\
\cline { 2 - 6 } Border & -0.069 & 0.382 & -6.054 & 4.708 & 0.505 \\
Area & $\boldsymbol{\beta}$ & $\boldsymbol{\rho}$ & $\mathbf{t}_{\boldsymbol{\beta}}$ & $\mathbf{t}_{\boldsymbol{\rho}}$ & $\mathbf{R}^{\mathbf{2}}$ \\
\cline { 2 - 6 } All & -0.049 & 0.804 & -3.777 & 8.466 & 0.581 \\
Area & -0.038 & $\boldsymbol{\rho}$ & $\mathbf{t}_{\boldsymbol{\beta}}$ & $\mathbf{t}_{\boldsymbol{\rho}}$ & $\mathbf{R}^{\mathbf{2}}$ \\
\cline { 2 - 6 } & & 0.883 & -6.387 & 13.976 & 0.666 \\
\hline
\end{tabular}

The tables above include the results of absolute $\beta$-convergence in SLM and SEM models. As the parameter estimation results show, the estimated value of the coefficient $\beta$ of coastal, border and the whole provinces are all negative. In SLM model, the judgment factor of coastal and border provinces $\beta$ is significant under the significance level of $5 \%$ which shows the absolute $\beta$-convergence of coastal and border provinces in recent years to a certain extent. However, in the estimation result of SEM model, all statistics indexes pass the test under the level of 5\%. In conclusion, SEM model shows a better goodness of fit than SLM model, which indicates the effect of spatial interaction on regional economic growth, and agrees with the existence of spatial interaction.

\section{The Empirical Analysis on the Club Convergence of Economic Growth between Coastal and Border Provinces in China}

Many economists suppose that the economies with different structures and initial conditions develop to different states, yet similar economies converge. There was a big economic gap between China's coastal and border provinces before 2013, but the implementation of "Belt and Road Initiative" strategy brought a total change to the economic growth of these two economics. And in this section, we will investigate the relationship between the two with the analysis of club convergence.

We examine the economic convergent relationship under the unit root test and co-integration test on the time series of
GDP per capita in the form of logarithm. The results of ADF test on the stationarity in the time series of GDP per capita are as follows:

TABLE VII. ADF TEST RESULTS OF COASTAL AND BORDER POVINCES

\begin{tabular}{|c|c|c|c|c|c|}
\hline Region & $\begin{array}{c}\text { ADF } \\
\text { Statistic }\end{array}$ & $\begin{array}{c}\mathbf{1}^{\text {st }} \text { diff. of } \\
\text { ADF Statistic }\end{array}$ & PR & Type & $\begin{array}{c}\text { Conclusio } \\
\mathbf{n}\end{array}$ \\
\hline Coastal & -0.3943 & -7.0950 & 0.0188 & $(\mathrm{c}, \mathrm{t}, 1)$ & Single \\
\hline Border & -0.9799 & -61.1102 & 0.0001 & $(\mathrm{c}, \mathrm{t}, 1)$ & Single \\
\hline
\end{tabular}

As the significant level of ADF test on the time sequence of the economics' GDP per capita is higher than the critical value of $5 \%$, it indicates that both sequences are non-stationary. And they are first order single sequence according to the result that their ADF test statistics are less than the critical value.

In order to judge whether the economic growth converges in the two regions of China, we use the method of Johanson to test on the co-integration relationship, where the results are as follows:

TABLE VIII. THE RESULTS OF JOHANSON TEST IN COASTAL AND BORDER PROVINCES

\begin{tabular}{|c|c|c|c|c|}
\hline & Trace statistics & $\mathbf{R}$ & $\mathbf{0 . 0 5}$ critical value & PR \\
\hline Case 1 & 6.7786 & None & 15.4947 & 0.6035 \\
\hline Case 2 & 3.2456 & At most 1 & 3.8415 & 0.0716 \\
\hline
\end{tabular}

From the results above, there appears insignificant trace statistics in the time sequence of GDP per capita of coastal and border provinces, which indicates there is no co-integration relationship between them. And we come to the conclusion that the economies do not converge because of the divergence in structure and initial condition, since the implement of "The Belt and Road" in year 2013.

The Quantile Regression Analysis on the Economic Growth of Coastal and Border Provinces or Districts in China.

It is necessary to conduct quantile regression using panel data model to obtain the estimation result with higher significant level when the least squares regression cannot achieve the best result. Since there are no significant explanatory variables in the least squares regression analysis, it's inappropriate to implement quantile regression. Therefore, we carry out the quantile regression analysis with GDP per capita as the explained variable and explanatory variables such as residents' consumption level $X_{3}$, urban road area per capital $X_{12}$, output value of secondary industry/GDPX $X_{9}$, local budgetary expenditure $X_{6}$, total fixed asset investment $X_{1}$, road area $X_{11}$, to analysis the different results of two methods in the panel data model.

TABLE IX. COMPARISON OF THE RESUlT OF LEAST SQUARES REGRESSION AND QUANTILE REGRESSION (FIXED EFFECT MODEL)

\begin{tabular}{|c|c|c|c|c|c|c|c|}
\hline & & \multirow{2}{*}{ OLS } & \multicolumn{5}{|c|}{ Quantile Regression } \\
\hline & & & 0.1 & 0.25 & 0.5 & 0.75 & 0.9 \\
\hline \multirow{2}{*}{$\mathrm{C}$} & COEFF & $\begin{array}{c}-40880 . \\
8\end{array}$ & $\begin{array}{c}-20052 . \\
5\end{array}$ & $\begin{array}{c}-22213 . \\
70\end{array}$ & $\begin{array}{c}-11206 . \\
80\end{array}$ & $\begin{array}{c}-26011 . \\
90\end{array}$ & $\begin{array}{c}-37743 . \\
30\end{array}$ \\
\hline & $\begin{array}{l}\text { T-Statisti } \\
\text { cs }\end{array}$ & $\begin{array}{c}-3.813 \\
4^{*}\end{array}$ & -2.12 & -1.90 & -1.63 & -3.50 & -6.51 \\
\hline \multirow{2}{*}{$\mathrm{X}_{3}$} & COEFF & 2.73 & 2.52 & 2.56 & 2.55 & 3.21 & 3.34 \\
\hline & $\begin{array}{l}\text { T-Statisti } \\
\text { cs }\end{array}$ & $22.29^{*}$ & 40.76 & 29.53 & 15.12 & 12.67 & 14.96 \\
\hline
\end{tabular}




\begin{tabular}{|c|c|c|c|c|c|c|c|}
\hline \multicolumn{8}{|c|}{ Table IX, cont. } \\
\hline \multirow{2}{*}{$\begin{array}{c}\mathrm{X}_{1} \\
2\end{array}$} & COEFF & 882.10 & 49.73 & 257.46 & 655.42 & 1320.87 & 1819.73 \\
\hline & $\begin{array}{c}\text { T-Statisti } \\
\text { cs }\end{array}$ & $5.61 *$ & 0.34 & 1.22 & 2.56 & 3.54 & 6.75 \\
\hline \multirow{2}{*}{$\mathrm{X}_{9}$} & COEFF & $\begin{array}{c}52800.9 \\
4\end{array}$ & $\begin{array}{c}43338.4 \\
8\end{array}$ & $\begin{array}{c}43468.3 \\
4\end{array}$ & $\begin{array}{c}19012.9 \\
2\end{array}$ & $\begin{array}{c}32814.9 \\
0\end{array}$ & $\begin{array}{c}51915.4 \\
0\end{array}$ \\
\hline & $\begin{array}{c}\text { T-Statisti } \\
\text { cs }\end{array}$ & 4.76 & 2.64 & 2.17 & 2.39 & 3.21 & 3.87 \\
\hline \multirow{2}{*}{$\mathrm{X}_{6}$} & COEFF & -2.92 & -1.91 & -1.76 & -2.27 & -3.96 & -1.48 \\
\hline & $\begin{array}{c}\text { T-Statisti } \\
\text { cs }\end{array}$ & -4.42 & -2.08 & -1.47 & -2.00 & -2.96 & -1.10 \\
\hline \multirow{2}{*}{$\mathrm{X}_{1}$} & COEFF & 0.44 & 0.52 & 0.47 & 0.60 & 0.44 & -0.14 \\
\hline & $\begin{array}{c}\text { T-Statisti } \\
\text { cs }\end{array}$ & $2.59^{*}$ & 3.56 & 2.32 & 3.26 & 1.65 & -0.64 \\
\hline \multirow{2}{*}{$\begin{array}{c}\mathrm{X}_{1} \\
1\end{array}$} & COEFF & $\begin{array}{c}26901.7 \\
0\end{array}$ & 0.027 & 0.00 & -0.034 & 0.01 & -0.17 \\
\hline & $\begin{array}{c}\text { T-Statisti } \\
\text { cs }\end{array}$ & $\begin{array}{c}1.6781 * \\
* *\end{array}$ & -0.49 & 0.01 & -0.55 & 0.05 & -1.61 \\
\hline & oefficient & 0.93 & 0.76 & 0.75 & 0.74 & 0.76 & 0.79 \\
\hline
\end{tabular}

Remark: COEFF refers to coefficient, *(**, ***) denote the critical value corresponding to the significance level of $1 \%(5 \%, 10 \%)$, and De-Coefficient indicates goodness of fit.

\section{1) Analysis of OLS Estimation Results:}

The results indicate that the sample data fits the model well with the decision coefficient $R^{2}=0.9254$. Except that the explanatory variable $X_{11}$ has a significant influence under the level of $\alpha=0.1$, the regression coefficient of other variables are significant under the level of $\alpha=0.1$.

\section{2) Analysis of Quantile Regression:}

The estimated value of regression differs under different quantiles, that is explanatory variables have different effect on the explained variable under different levels. From the results we know, the higher decision coefficient indicates a better goodness of fit, and the sign of quantile regression resembles that of least squares method. However, the change of GDP shows some trend as the explanatory variables move to different spaces in the conditional distribution. For example, the coefficient of urban road area per capital $X_{12}$ increases as the conditional quantile changes from lower to higher, but that of output value of secondary industry/GDP $X_{9}$ decreases first and increases later, which value are respectively 43468.34 , 19012.92 and 51915.4 at the quantile of $0.25,0.5$ and 0.9. So it shows that $X_{9}$ has the most significant enhancement at the quantile of 0.9 than others. In all, the quantile regression gives more detailed information than the least squares regression with more robust results.

\section{CONCLUSION}

The paper conducts the analysis research on the economic growth convergence of 19 selected coastal and border provinces or districts from 2008 to 2015, with using several methods of spatial econometrics such as $\sigma$-convergence, $\beta$-convergence, club convergence, quantile regression and so on. First, the economic growth of overall provinces manifests the trend of $\sigma$-convergence, with the discrepancy of real
GDP per capita in coastal provinces reducing to a steady state but no significant convergence in that of border provinces. Furthermore, with the consideration of spatial correlation, the real GDP per capita of 19 provinces show $\beta$-convergence in the SEM model and has better goodness of fit with it than spatial leg model, which means the necessity to consider the spatial interaction in the analysis of economic growth.

Nevertheless, there is no co-interaction relationship between the region of coastal and border when we carry out the club convergence analysis. So we get to the conclusion that there is no sign of club convergence between the two region in the short term because of the difference of initial conditions and economic structures.

In this research, it is obvious to conclude that the elements do affect the regional economic growth convergence, such as material capital, human resource endowment, policy implementation and so on. Owing to the discrepancy of regional economic convergence, different district should consider suitable adjustment on capital investment and industrial structure. As economy in the process of globalization, there appears more significant mutual driving force in the economic growth of two adjacent districts, which suggests that the state should narrow the divergence of relevant policy to promote the regional economic growth.

\section{ACKNOWLEDGMENT}

This research was finally supported by Student Research Training Program in Southwest Jiaotong University of Sichuan Province (Grant No.2016101).

\section{REFERENCES}

[1] Solow, R.M., 1956. A Contribution to the Theory of Economic Growth Quarterly Journal of Economics70:65-94;

[2] CHEN Xiaoling, LI Guoping, Spatial Panel Data Model Analysis of Regional Economic Convergence in China, Economic Science, 2006(5)(In Chinese);

[3] HONG Guozhi, HU Huaying, LI Huan, Spatial Econometric Analysis of Regional Economic Development Convergence in China, Journal of Geography,Vol.65, No.12(In Chinese);

[4] HE Xionglang, ZHENG Changde, YANG Xia, Theoretical and Empirical Analysis on Spatial Relevance and Dynamic Convergence of Regional Economic Growth in China-- Empirical Evidence Based on Panel Data from 1953 to 2010, Fiscal Research, 2013(7)(In Chinese);

[5] CAI Fang, DU Yang, The Enlightenment of the Convergence and Difference of Economic Growth in China on the Western Development Strategy[J], Economics Research, 2000 (10) : 30-37(In Chinese);

[6] WANG Liang, The Mechanism of Existence and Formation of the Convergence Hypothesis of Economic Growth, Economic Science Press,PP:1-4(In Chinese);

[7] Wikipedia: Gini Coefficient, February 27th 2017,

[8] https://en.wikipedia.org/wiki/Gini_coefficient\#Calculationhttps://en.wik ipedia.org/wiki/Gini_coefficient\#Calculation;

[9] Baidu Library, Theil Index Formula and Calculation Method;

[10] http://wenku.baidu.com/link?url=ZCVZtLvcG4HgJAkOzeeVBdS2U44 awxtZ1uCCJPfSfasifkOATZEdSMTat3IedUcMYYRdmAcx9rp-ASUR GMsw2ajvjFTZAxzL7GtD6VRE_Mm(In Chinese);

[11] ZHAO Wei, MA Ruiyong, The Difference of Regional Financial Growth in China - Based on the Measurement of Theil Index, Vol.26, No.1(In Chinese); 
[12] MATLAB:

$$
\text { Moran }
$$

http://blog.sciencenet.cn/blog-1148346-933485.html(In Chinese);

[13] SHI Xiusong, ZHAO Shudong, Regional Difference of China 's Economic Growth and Its Convergence Mechanism(1978 2009)[J], The Journal of Quantitative \& Technical Economics, 2011(1) (In Chinese);

I's

(1)

(1)

Financial Development and Economic Convergence, Statistics \&
(14) Decision, 2014(23) (In Chinese);

[15] YANG Chunsheng, Convergence Analysis of Regional Economic Growth in China, http://210.45.208.81/(In Chinese);

[16] Bernard, A.B. and Durlauf, S.N., 1996.Interpreting tests of the convergence hypothesis. Journal of Econometrics,71;

[17] Koenker, Bassett. Regression Quantiles[J]. Econometrica,1978,(46) 